\title{
DEGUM-Förderpreisträger der Sektion Kopf-Hals 2019
}

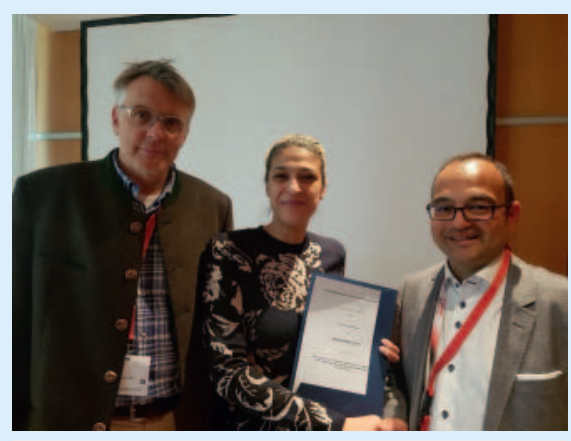

Förderpreisträgerin Dr. N. Mansour (Mitte) mit dem Präsidenten der DEGUM, Prof. P. Jecker (links), und dem Leiter der Sektion Kopf-Hals, Prof. A. Bozzato (rechts)

(Foto: PD Dr. G. F. Volk).

Während des 43. Dreiländertreffens in Leipzig wurde der DEGUM-Förderpreis der Sektion Kopf-Hals verliehen. Im Rahmen der Mitgliederversammlung der Sektion wurde Frau Dr. Naglaa Mansour von der Klinik für Hals-, Nasen- und Ohrenheilkunde des Universitätsklinikums Freiburg mit dem Förderpreis für ihre Habilitationsarbeit
„Elastografische und kontrastverstärkte Ultraschallmethoden im Kopf-Hals-Bereich unter besonderer Berücksichtigung der Ohrspeicheldrüse“ ausgezeichnet.

Unsere herzlichsten Glückwünsche an die Preisträgerin.

\section{Sektion Kopf-Hals schreibt}

\section{Förderpreis aus - jetzt}

\section{bewerben}

Die Sektion Kopf-Hals der Deutschen Gesellschaft für Ultraschall in der Medizin (DEGUM) schreibt auch für 2020 den Förderpreis der Sektion aus. Der Preis ist mit 500 Euro dotiert und richtet sich an Wissenschaftler der KopfHals-Sonografie, die sich mit außergewöhnlichen Publikationen oder einer Habilitationsschrift der Kopf-Hals-Sonografie verdient gemacht haben.

Autoren, die bereits den DEGUM-Preis verliehen bekommen haben, können sich nicht ein zweites Mal bewerben. Es ist jedoch möglich, dass eine abgelehnte Arbeit im Folgejahr erneut eingereicht wird.

Der Antrag ist formlos auf elektronischem Weg unter Anlage der eingereichten Publikation bis zum 30. April 2020 an die DEGUMGeschäftsstelle (DEGUM e. V., Charlottenstr. 79/80, 10117 Berlin, geschaeftsstelle@ degum.de) zu richten.

Die Preisverleihung erfolgt während des Treffens der Sektion Kopf-Hals im Herbst 2020. Die Anwesenheit des Preisträgers ist hierbei obligat. Im Rahmen der Preisverleihung wird der Preisträger bzw. die Preisträgerin aufgefordert, ihre Arbeit in einem Kurzreferat vorzustellen.

Prof. Dr. med. A. Bozzato Leiter der Sektion Kopf-Hals 